\title{
Subtherpeutic anti-factor Xa levels in patient with ascites receiving subcutaneous enoxaparin injection at abdominal wall
}

Vichapat Tharanon $^{1}$ and Theerasuk Kawamatawong ${ }^{1}$

${ }^{1}$ Mahidol University Faculty of Medicine Ramathibodi Hospital

September 25, 2021

\begin{abstract}
Enoxaparin is a low-molecular weight heparin for management of the thromboembolic disorders. In practice, subcutaneous (SC) enoxaparin at abdominal wall for patient with ascites might be indeterminate. It is noticed that SC enoxaparin administration in patient with ascites likely affected the anti-factor Xa level of enoxaparin.
\end{abstract}

\section{Hosted file}

manuscript_Clinical Case_V.1_26.8.21.doc available at https://authorea.com/users/436490/ articles/538770-subtherpeutic-anti-factor-xa-levels-in-patient-with-ascites-receivingsubcutaneous-enoxaparin-injection-at-abdominal-wall

\section{Hosted file}

Table 1 antifactorXa level.docx available at https://authorea.com/users/436490/articles/ 538770-subtherpeutic-anti-factor-xa-levels-in-patient-with-ascites-receivingsubcutaneous-enoxaparin-injection-at-abdominal-wall

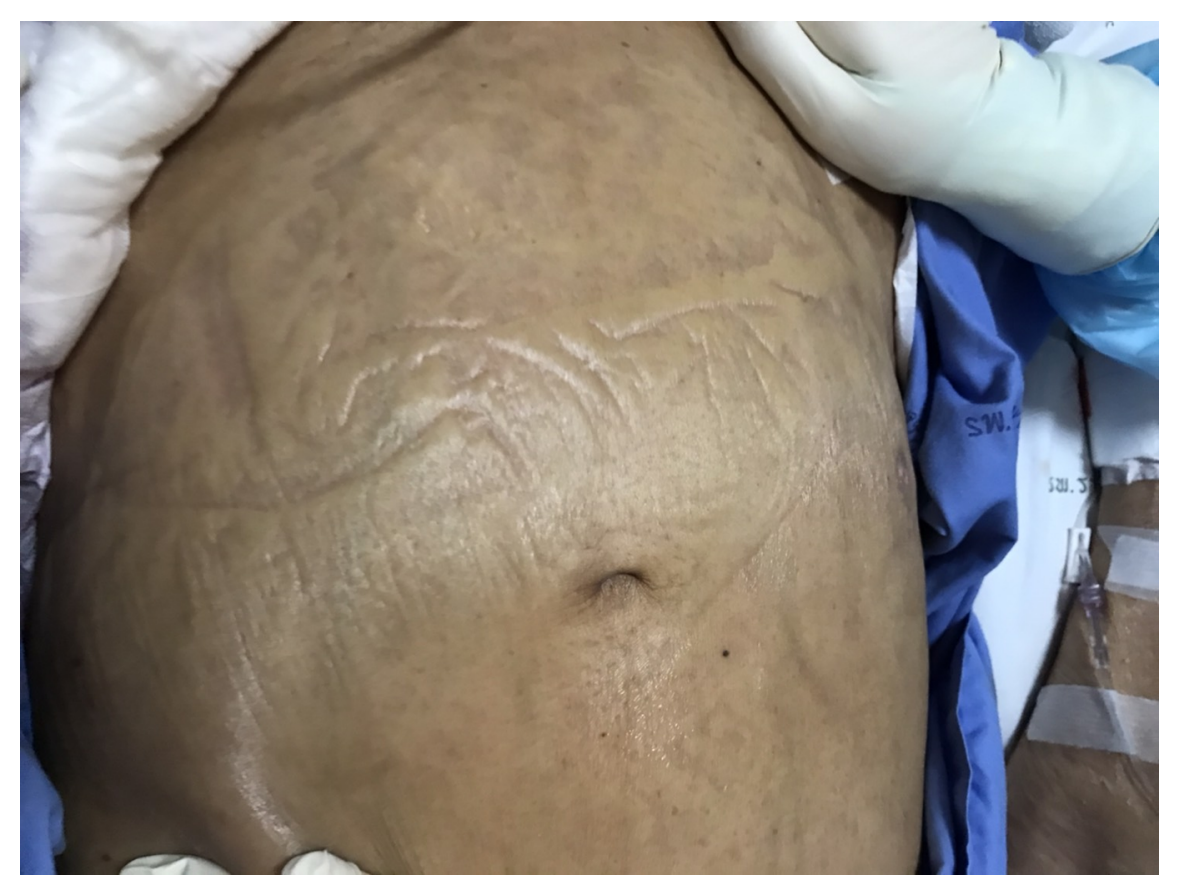




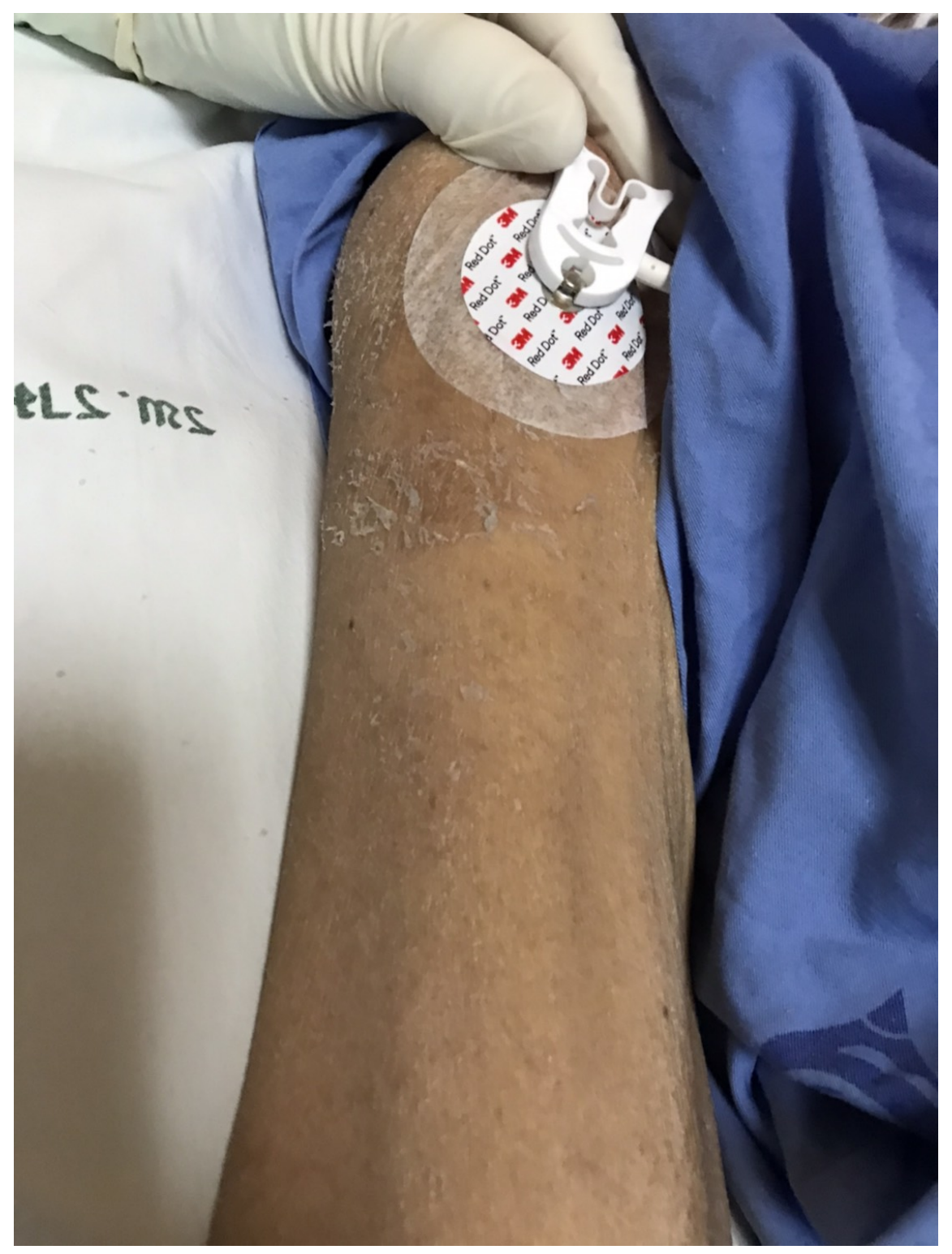

